\title{
Development of a vehicle emission inventory with high temporal-spatial resolution based on NRT traffic data and its impact on air pollution in Beijing - Part 1: Development and evaluation of vehicle emission inventory
}

\author{
Boyu Jing ${ }^{1}$, Lin Wu ${ }^{1}$, Hongjun Mao ${ }^{1}$, Sunning Gong ${ }^{2}$, Jianjun $\mathrm{He}^{1}$, Chao Zou ${ }^{1}$, Guohua Song ${ }^{3}$, Xiaoyu $\mathrm{Li}^{1}$, and \\ Zhong $\mathrm{Wu}^{4}$ \\ ${ }^{1}$ The College of Environmental Science \& Engineering, Nankai University, Tianjin, China \\ ${ }^{2}$ Chinese Academy of Meteorological Sciences, China Meteorological Administration, Beijing, China \\ ${ }^{3}$ MOE Key Laboratory for Urban Transportation Complex Systems Theory and Technology, Beijing Jiaotong University, \\ Beijing, China \\ ${ }^{4}$ College of Civil and Transportation Engineering, Hohai University, Suzhou, China
}

Correspondence to: Hongjun Mao (hongjun_mao@hotmail.com) and Sunning Gong (sunling@cams.cma.gov.cn)

Received: 30 April 2015 - Published in Atmos. Chem. Phys. Discuss.: 5 October 2015

Revised: 22 January 2016 - Accepted: 13 February 2016 - Published: 10 March 2016

\begin{abstract}
This paper presents a bottom-up methodology based on the local emission factors, complemented with the widely used emission factors of Computer Programme to Calculate Emissions from Road Transport (COPERT) model and near-real-time traffic data on road segments to develop a vehicle emission inventory with high temporal-spatial resolution (HTSVE) for the Beijing urban area. To simulate real-world vehicle emissions accurately, the road has been divided into segments according to the driving cycle (traffic speed) on this road segment. The results show that the vehicle emissions of $\mathrm{NO}_{x}, \mathrm{CO}, \mathrm{HC}$ and $\mathrm{PM}$ were $10.54 \times 10^{4}$, $42.51 \times 10^{4}$ and $2.13 \times 10^{4}$ and $0.41 \times 10^{4} \mathrm{Mg}$ respectively. The vehicle emissions and fuel consumption estimated by the model were compared with the China Vehicle Emission Control Annual Report and fuel sales thereafter. The gridbased emissions were also compared with the vehicular emission inventory developed by the macro-scale approach. This method indicates that the bottom-up approach better estimates the levels and spatial distribution of vehicle emissions than the macro-scale method, which relies on more information. Based on the results of this study, improved air quality simulation and the contribution of vehicle emissions to ambient pollutant concentration in Beijing have been investigated in a companion paper (He et al., 2016).
\end{abstract}

\section{Introduction}

Air pollutants from gases to particulates in megacities are associated with a mixture of various sources, including primary/secondary and natural/anthropogenic sources, and air pollution has become a major human health concern (An et al., 2013). Emissions from human activities and natural processes can react with ozone and light to form secondary pollutants, which are more difficult to analyse. Resulting from the complexities of local to regional emissions, the term "complex atmospheric pollution" has emerged in the last decade (Chan and Yao, 2008; Fang et al., 2009). Driven by rapid industrialization and urbanization, Beijing, the capital city of China, has received extensive global attention regarding its contribution to the atmospheric environment. $\mathrm{Nu}-$ merical model simulation is a very effective tool for proportionally estimating contributions to air pollution from various sources under certain atmospheric conditions (Cheng et al., 2007; Wang and Xie, 2009). The accuracy of emission source inventory is the key to air quality numerical simulation. In recent years, transportation emissions have become the most significant emission source in Chinese megacities (e.g. Beijing) (He et al., 2002). There are differing opinions in quantitative research regarding the pollution contribution 
of vehicle emissions (Song et al., 2006; Cheng et al., 2013; Wu et al., 2014).

Numerical model simulation is an effective method of quantifying a portion of on-road vehicle emissions accounting for air pollution, particularly in different periods and regions. However, numerical model simulation relies heavily on the accuracy of mesoscale meteorological models and emission inventories, which have shown significant improvements in the past two decades due to the development of new physical parameterization and data assimilation techniques. Although plenty of research exists on the climate characteristics of Beijing (An et al., 2007; Wu et al., 2014), no integrated emission inventory model reflects simultaneously the factors of traffic volume, speed and fleet composition at a particular road segment. Therefore, the accuracy of emission source inventory in an air quality numerical simulation has become a challenge.

The establishment of vehicle emission inventory requires a large amount of data, such as emission factors, traffic activity, fleet composition and the combined situation of these factors, which is strongly influenced by the local driving circle, road information, traffic characteristics, etc. Until recently, most of the emission inventories in Chinese cities have been developed by utilizing the MOBILE model from the US Environmental Protection Agency (EPA) or similar macro-scale models (Hao et al., 2000; Fu et al., 2001; Cai and Xie, 2007; Guo et al., 2007), in which the inventory approach is defined as a top-down method. For this method, the emission factors are uniform for the same vehicle category in the entire study region, combined with the number of kilometres travelled (VKT) for each vehicle fleet, to estimate the average emissions on a large geographic scale. Then, emissions are allocated as required by the air quality model to hourly or daily emissions by the local time-varying characteristic and allocated to grid cells by the local population and/or road density.

However, there are some limitations in the top-down methodology. For example, the same emissions factors under average speed circumstances cannot reflect the influences of velocity changes at different road segments at different times; the spatial and temporal distribution method cannot reflect the dramatic difference of traffic flow characteristics on various road segments (Reynolds, 2000). Thus, the macro-scale emission inventories may not reflect the real emission conditions for on-road vehicles in the city, and the low spatial and temporal resolutions are also limited in the application of air quality models. Additionally, because the strategies are converted to individual vehicles (e.g. requiring stricter emission limits for new vehicles, strengthening the management of in-use vehicles, eliminating high-emitting vehicles) and transportation management (e.g. developing public transportation, improving travel conditions, adopting traffic control measures), the top-down inventories are not able to assess the effects of air quality improvement from the implemented strategies because of the limited reflection of spatial and temporal variation in complex urban traffic conditions. Therefore, more accurate and higher-resolution vehicle emission inventories are currently needed in Beijing.

There are two obstacles in the establishment of a vehicle emission inventory: reliable vehicular emission factors based on the local vehicle emission conditions and comprehensive traffic data (e.g. traffic volume, speed, fleet composition) displaying the traffic flow characteristics of each road (Wang et al., 2008). With the increase of research, some higher-resolution vehicle emission inventories in Chinese cities were established based on bottom-up methodology (Wang et al., 2008; Huo et al., 2009; Wang and Xie, 2009; Zhou et al., 2015). However, most of those inventories had some limitations regarding reflection on real-time variation of vehicle emissions on each road due to the lack of collection methodology of real-time traffic data.

Driven by the development of traffic data observation technology, the conventional loop coil detector and video detector are gradually being replaced by a higher cost-benefit sensor system. This system now makes the acquisition of mass fine traffic data feasible. Meanwhile, the rapid development of geographic information system (GIS) and Global Positioning System (GPS) technology makes a strong connection between traffic activity data and road information. Infrastructure sensors and floating cars are believed to be the main sources for the current traffic data collection. The infrastructure sensors consist of fixed-point detectors installed in roads, and floating cars are mobile probe vehicles (e.g. buses and taxis) with GPS positioning devices. It is difficult to cover the entire road network of the city with the information collected by the infrastructure sensors from a static point on a road, which is lacking space coherence (Naranjo et al., 2012).

Floating cars collect information from the vehicles that travelled on the road segments, data which are then utilized to estimate the average speeds, traffic intensity and other relevant conditions (e.g. congestion status). However, the temporal and spatial resolutions of current traffic data are too low to establish hour-scale and road-scale vehicle emission inventory. It needs near-real-time (NRT) traffic data on the entire network, which can be collected by integrating the floating car data, radio frequency identification data and video identification data.

The purpose of this paper is to develop a high temporalspatial resolution vehicle emission (HTSVE) inventory for Beijing based on local emission factors and NRT traffic data using a bottom-up methodology. The road system of Beijing, the capital of China, consists of urban freeways, artery roads, collector roads and local roads. The scope of this research is the area within the sixth ring road and the surrounding area, which is the main activity area for people in Beijing. This project is divided into two parts: Part 1 elaborates on the development of a high temporal-spatial resolution vehicle emission inventory in Beijing, and Part 2 analyses the effect of vehicle emissions on urban air quality. 


\section{Methodology and data}

In this study, a vehicle emission inventory model based on bottom-up methodology was used to develop an inventory for vehicular emissions. The model simulated the emissions for each road segment during each hour, depending on the traffic volume and the emission rates of these vehicles on the road segment during the following period:

$$
Q_{i, j}^{p}=\sum_{c} \mathrm{EF}_{c, v}^{p} \times \mathrm{VT}_{c, i, j} \times L_{i},
$$

where $Q_{i, j}^{p}$ is the emission of pollutant $p$ on road segment $i$ at moment $j\left(\mathrm{~g} \mathrm{~h}^{-1}\right) ; \mathrm{EF}_{c, v}^{p}$ is the emission factor of pollutant $p$ for vehicle category $c$ at speed $v\left(\mathrm{~g} \mathrm{~km}^{-1}\right)$; $\mathrm{VT}_{c, i, j}$ is the traffic volume of category $c$ on road $i$ at moment $j\left(\operatorname{veh~h}^{-1}\right)$; $\mathrm{L}_{i}$ is the length of road $i(\mathrm{~km})$. The total urban emissions is the sum of the vehicle emissions on all roads.

There are three necessary elements for the model: emission factors, vehicle activity and road segment information. Emission factors are based on the mass of the laboratory measurement and the on-road measurement data. The vehicle activity included traffic volume, average speed and fleet composition on the entire road segment. Road information consists of road length, line number and road type (including freeway, artery road, collector road and local road) of each road segment. In terms of the traffic speed on this segment, the road has been divided into fine segmentations and was grouped as urban freeway, artery road or local road (a local road consists of collector roads and residential roads because of the negligible differences between them in Beijing).

\subsection{Emission factors}

It is widely known that vehicle emission rates are largely related to vehicle characteristics, including vehicle classification, utilization parameters, operating conditions and environmental conditions. The vehicle characteristics comprise of vehicle category, fuel type and vehicle emission control level; the utilization parameters involve vehicle age, accumulated mileage, inspection and maintenance; the operating conditions include cold or hot starts, average vehicle speed and the influence of driver behaviour; the environmental conditions include ambient temperature, humidity and altitude.

Due to the significant differences among different vehicle classification, the emission factors were classified by the vehicle classification and modified by the utilization parameters, operating conditions and environmental conditions in Beijing. With the existing classification method of the Ministry of Environmental Protection and the Ministry of Transport in China, vehicles have been classified as follows: (1) vehicle category was classed as a light duty vehicle (LDV), middle duty vehicle (MDV), heavy duty vehicle (HDV), light duty truck (LDT), middle duty truck (MDT), heavy duty truck (HDT), bus or taxi; (2) fuel type was classified as gasoline, diesel or other (e.g. liquefied natural gas or compressed natural gas); (3) vehicle emission control levels were classified as Pre-China I, China I, China II, China III, China IV and China V, which were respectively equivalent to Pre-Euro, Euro I, Euro II, Euro III, Euro IV and Euro V.

The emission factors were corrected by the widely used emission factors of the Computer Programme to Calculate Emissions from Road Transport (COPERT) model on the basis of local emission factors. The local emission factors were collected from a mass of measuring data from the Tsinghua University and China Automotive Technology \& Research Center, such as bench testing and on-road vehicle emissions measurements in Beijing (Huo et al., 2009; Hu et al., 2012; Wu et al., 2012; Wang et al., 2013). Meanwhile, the fuel consumption factors for vehicles were measured and included in this model. The emission factors of $\mathrm{NO}_{x}, \mathrm{HC}, \mathrm{CO}, \mathrm{PM}$ and the fuel consumption factors of gasoline and diesel are shown in Fig. 1.

\subsection{Vehicle activity}

The model based on the NRT traffic volume and speed of the road segment, which were collected by the NRT floating car data and video identification data in 2013, was utilized to simulate the emission inventory. The fleet composition was collected by traffic survey data and vehicle registration information in Beijing.

According to the GPS data from on-road vehicles, the floating car data covered information within 2 weeks for the entire city. The video cameras were installed on typical roads to gather video identification data. The data collection points are shown in Fig. 2. The traffic survey data were collected from a video field survey of more than $300 \mathrm{~min}$ on typical roads.

\subsubsection{Average running speed based on floating car data}

Floating car data technology is recently believed to be an advanced technological method to collect traffic information in intelligent transport systems (ITSs). Based on GPS devices, floating cars periodically record information such as time, speed, latitude and longitude while moving and send those data back to an information centre via on-board wireless transmission equipment. In this research, the floating car data were processed to calculate the average speed following the steps below: (1) the unqualified data of each transfer interval longer than $150 \mathrm{~s}$ at speeds over $120 \mathrm{~km} \mathrm{~h}^{-1}$ were filtered; (2) the position data from floating car within the road segment were fixed by the map algorithm by matching and route estimation; (3) the single vehicle speed was calculated by the travel length divided by the travel time; (4) the single vehicle speed on the same road segment within an hour were averaged to find the average running speed value. Therefore, the hourly average running speed on each road segment is obtained from the floating car data collection and processing. The average vehicle running speed is one of the important 


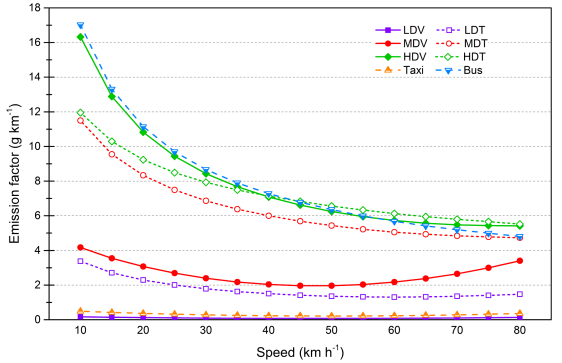

(a)

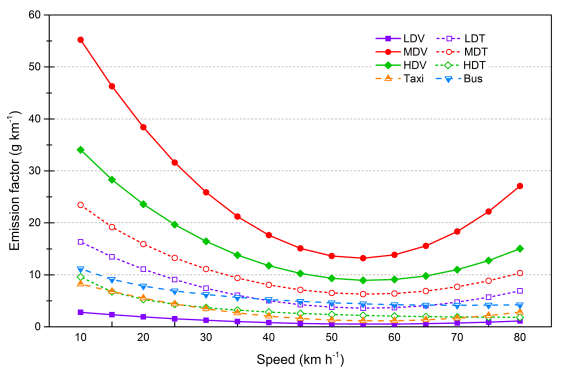

(c)

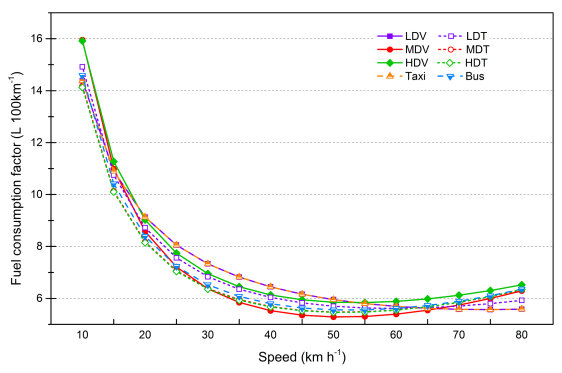

(e)

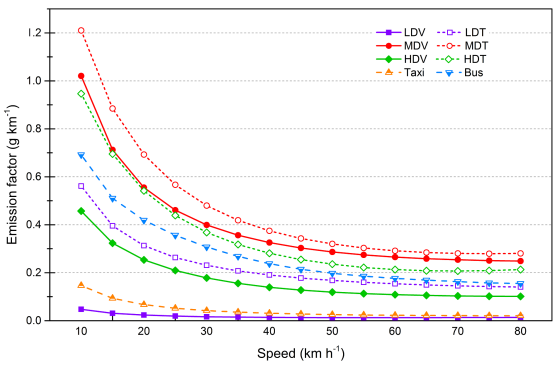

(b)

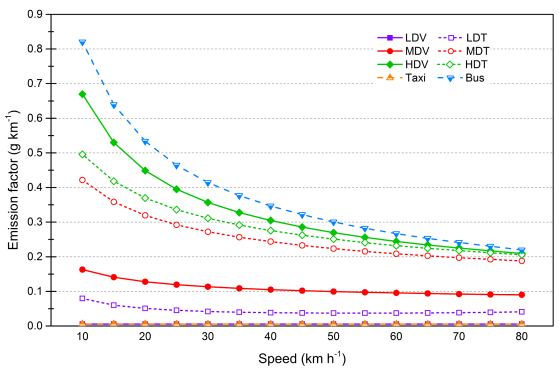

(d)

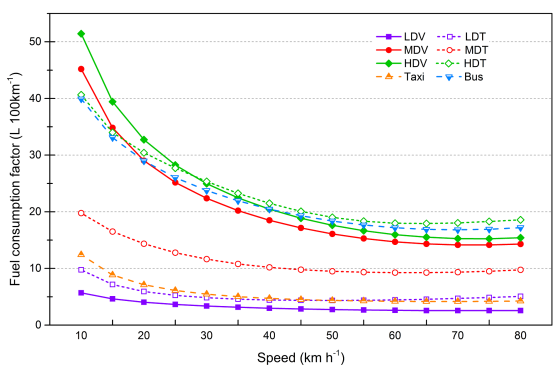

(f)

Figure 1. Emission factors of $\mathrm{NO}_{x}, \mathrm{HC}, \mathrm{CO}, \mathrm{PM}$ and fuel consumption factors of gasoline and diesel (Huo et al., 2009; Hu et al., 2012; Wu et al., 2012; Wang et al., 2013): (a) emission factors of $\mathrm{NO}_{x}$, (b) emission factors of $\mathrm{HC}$, (c) emission factors of CO, (d) emission factors of $\mathrm{PM}$, (e) fuel consumption of gasoline and (f) fuel consumption factors of diesel.

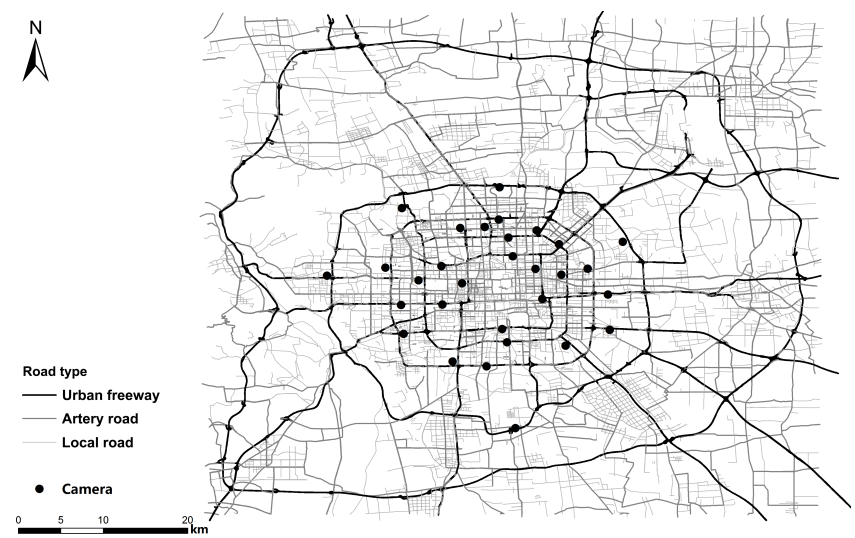

Figure 2. Point location of video cameras. parameters of traffic data and is utilized to estimate traffic flow.

\subsubsection{Traffic flow from speed}

The traffic volume was estimated by the average speed based on the relationship between the traffic speed and volume. The relationship between the traffic speed and volume and the same speed-flow model was established using models such as the Greenshield model, the Greenberg model and the Underwood model (Wang et al., 2013; Hooper et al., 2014).

According to the traffic volume observed by the video identification data and traffic speed estimated by floating car data, the speed-flow model for the traffic in Beijing was designed on every road segment and was grouped into three road types including the urban freeway, artery roads and local roads. In this study, the Greenshield, Greenberg and Un- 


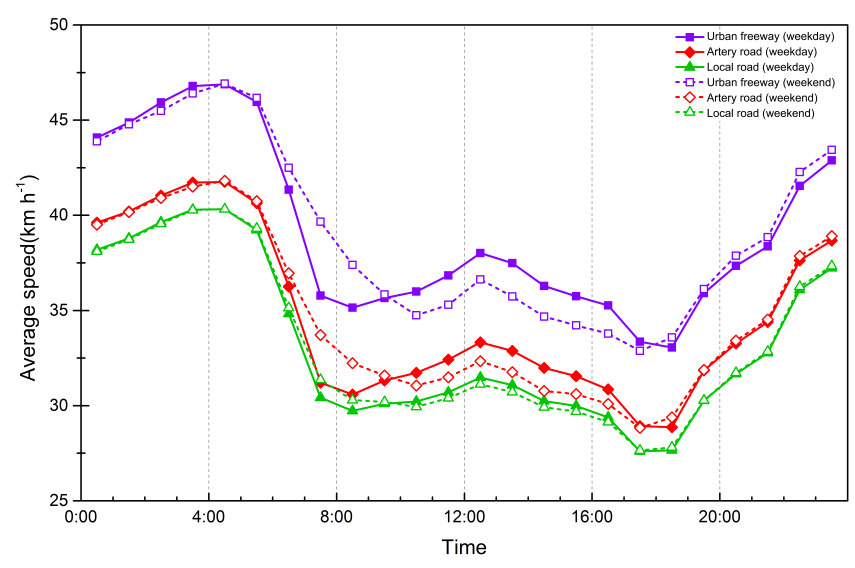

Figure 3. Hourly traffic average speed on different road types in Beijing.

derwood models were fitted for three road types. The Underwood model was used because it had the best goodness of fit $\left(R^{2}\right)$ among these models.

$V=k_{m} u \ln \frac{u_{\mathrm{f}}}{u}$

where $V$ is the traffic volume at speed $u\left(\mathrm{veh} \mathrm{h}^{-1}\right) ; u$ is the traffic speed $\left(\mathrm{km} \mathrm{h}^{-1}\right) ; k_{m}$ is the best fitting traffic density $\left(\right.$ veh $\left.\mathrm{km}^{-1}\right) ; u_{\mathrm{f}}$ is the free speed $\left(\mathrm{km} \mathrm{h}^{-1}\right) . k_{m}$ and $u_{\mathrm{f}}$ were determined by fitting the Underwood model based on the video identification data and the floating car data from the different road types.

\subsubsection{Vehicle fleet composition}

Considering the significant emission differences between different vehicles, more attention should be paid to emission control technologies (Heeb et al., 2003; Karlsson, 2004). The fleet composition of driving vehicles is estimated to calculate emissions based on vehicle information and the video data from typical roads in Beijing.

\section{Results and discussions}

\subsection{Traffic characteristics in Beijing}

Traffic speed, traffic volume and fleet composition show the main characteristics of vehicle activities that quantify vehicle emissions in Beijing. According to the floating GPS car data, the hourly average traffic speed fluctuates at different times throughout the day but shows similarity for the different road types. The daily average traffic speed on weekdays is close to the weekend speeds, as illustrated in Fig. 3; however, the trends of hourly traffic speed on the urban freeway and the artery roads changes significantly from weekdays to weekends. There are two low-speed valleys on weekdays during the early and afternoon peak hours at approximately 08:00

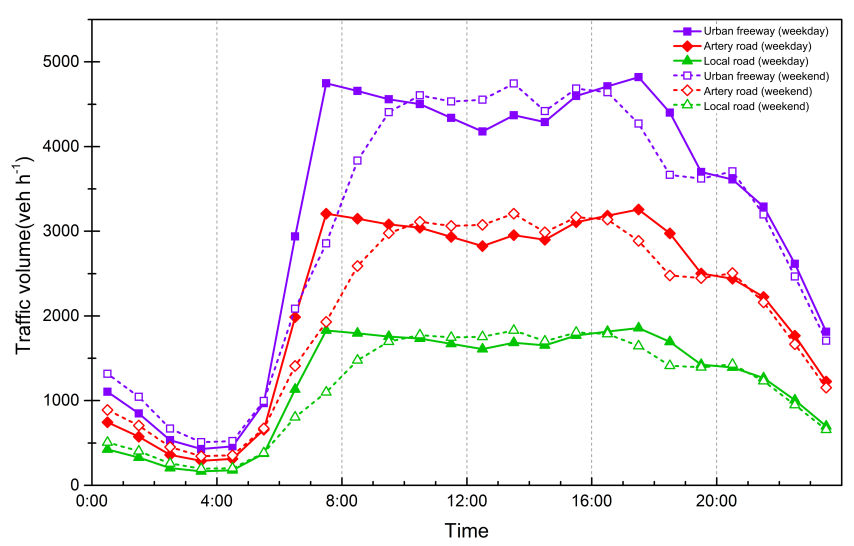

Figure 4. Hourly traffic volume on different road types in Beijing.

and 18:00 $(\mathrm{GMT}+8)$ respectively. On weekends, the early valley period appears $2 \mathrm{~h}$ later, and the late valley period appears $1 \mathrm{~h}$ earlier than on weekdays. The traffic speed is lower than that on weekdays during the off-peak hours. For the local road, the variation of traffic speed is similar between weekdays and weekends.

The traffic volume of vehicles contributes significantly to influence pollutant emissions. As shown in Fig. 4, the average daily traffic volume on weekdays is close to the traffic volume on weekends. However, the variation tendencies display a different picture during different moments between weekdays and weekends. The overall traffic volume changes dramatically at different times during a day, and two obvious peaks of traffic volume appear at 08:00 and 18:00. On weekends, the early peak period appears $2 \mathrm{~h}$ later, and the late peak period appears $1 \mathrm{~h}$ early than on weekdays: the variation extent around the traffic volume peak is significantly lower than on weekdays.

The contributions to emission vary significantly based on different types of vehicles. Therefore, the fleet composition is a major factor affecting the release of emissions, as shown in Table 1.

\subsection{Vehicle emission inventory}

\subsubsection{Emission inventory}

Using the methodology described above, a high temporalspatial resolution vehicle emission inventory was established in this study. The total daily emissions of each road, which is a sum of emissions during a $24 \mathrm{~h}$ period, is shown in Table 2 . The daily total emissions of the urban freeway, artery roads and local roads are $288.71 \mathrm{Mg}$ of $\mathrm{NO}_{x}, 58.29 \mathrm{Mg}$ of $\mathrm{HC}, 116.58 \mathrm{Mg}$ of $\mathrm{CO}$ and $11.24 \mathrm{Mg}$ of PM. It is clear that the emissions of each pollutant display a descending order for the urban freeway, the artery road and the local road. High emission intensity and the long length of the artery road (approximately $33 \%$ of total length of roads in Beijing) contribute to the highest emissions. Although the urban free- 
Table 1. Fleet composition in Beijing.

\begin{tabular}{lrrrrrrr}
\hline Vehicle types & Pre-China 1 & China 1 & China 2 & China 3 & China 4 & China 5 & Total \\
\hline LDV & $2.32 \%$ & $2.34 \%$ & $8.71 \%$ & $11.10 \%$ & $46.39 \%$ & $3.72 \%$ & $74.58 \%$ \\
MDV & $1.44 \%$ & $0.33 \%$ & $0.36 \%$ & $0.29 \%$ & $0.20 \%$ & $0.00 \%$ & $2.63 \%$ \\
HDV & $0.23 \%$ & $0.09 \%$ & $0.40 \%$ & $0.93 \%$ & $0.56 \%$ & $0.00 \%$ & $2.21 \%$ \\
LDT & $0.40 \%$ & $0.36 \%$ & $0.44 \%$ & $0.71 \%$ & $2.61 \%$ & $0.00 \%$ & $4.53 \%$ \\
MDT & $0.18 \%$ & $0.07 \%$ & $0.09 \%$ & $0.42 \%$ & $0.65 \%$ & $0.00 \%$ & $1.40 \%$ \\
HDT & $0.21 \%$ & $0.28 \%$ & $0.14 \%$ & $1.15 \%$ & $1.76 \%$ & $0.00 \%$ & $3.54 \%$ \\
Taxi & $0.00 \%$ & $0.00 \%$ & $1.68 \%$ & $3.06 \%$ & $3.76 \%$ & $0.35 \%$ & $8.84 \%$ \\
Bus & $0.02 \%$ & $0.10 \%$ & $0.53 \%$ & $0.99 \%$ & $0.63 \%$ & $0.00 \%$ & $2.27 \%$ \\
\hline
\end{tabular}

Table 2. Daily vehicle emission on different road types of Beijing (unit: $\mathrm{Mg} \mathrm{day}^{-1}$ ).

\begin{tabular}{llrrrrr}
\hline Date & Road type & Length $(\mathrm{km})$ & $\mathrm{NO}_{x}$ & $\mathrm{CO}$ & $\mathrm{HC}$ & $\mathrm{PM}$ \\
\hline \multirow{2}{*}{ Weekdays } & Urban freeway & 2169.49 & 111.09 & 447.12 & 22.40 & 4.33 \\
& Artery road & 3786.94 & 124.53 & 502.89 & 25.16 & 4.85 \\
& Local road & 4586.06 & 56.49 & 228.36 & 11.42 & 2.20 \\
\hline \multirow{2}{*}{ Weekends } & Urban freeway & 2169.49 & 95.39 & 383.79 & 19.21 & 3.71 \\
& Artery road & 3786.94 & 110.81 & 446.98 & 22.36 & 4.31 \\
& Local road & 4586.06 & 74.04 & 299.36 & 14.97 & 2.88 \\
\hline
\end{tabular}

way length is $2169 \mathrm{~km}$, accounting for $22 \%$ of total length of roads in Beijing, the emissions of the urban freeway account for more than $38 \%$ of the total emissions, which is a little lower than the artery roads for each type of pollutant. The local road emissions are lower than those on the urban freeways and artery roads, although the length of local roads is the longest in Beijing (approximately $38 \%$ of the total length of roads).

The spatial distributions of emissions among the night, offpeak hours, morning and afternoon peak hours are illustrated in Fig. 5. With the assistance of ArcGIS, vehicle emissions are estimated at a $1 \mathrm{~km} \times 1 \mathrm{~km}$ resolution for the Beijing urban area. The emission intensity of vehicles decreases from the centre to the periphery of the city with a radiating structure during the night, off-peak, morning and afternoon peak hours. The reason for the high emissions at the city centre is mainly caused by the high traffic volume and low vehicle speed. In the surrounding areas of Beijing, the high emissions are mostly distributed in the areas with the urban freeways and the major intersections.

As illustrated in Fig. 5, the northern areas have the highest emission intensities, the southern areas have the lowest emission intensities, and the emission intensities of eastern areas are slightly higher than the western areas. The difference of emissions among the various areas is mainly caused by the different degrees of prosperity. More business activities and human activities occur in the northern areas than other areas, leading to more intense traffic activities in the northern areas.

The emission intensity of 8:00 to 09:00 and 17:00 to 18:00 is much higher than for the rest of day because of high traffic volume during those times. Due to serious traffic congestion, vehicles emit more pollutants when they operate at low speed with frequent accelerations, decelerations and in idle mode.

\subsubsection{Temporal variation in emissions}

According to the emission factors and vehicle activities, the vehicle emission inventory model mentioned above was used to calculate the pollutant emissions rate. The emissions of $\mathrm{NO}_{x}, \mathrm{HC}, \mathrm{CO}$ and PM show similar trends within a day. For example, the emissions of $\mathrm{NO}_{x}$ vary throughout the day but reach agreement among the urban freeway, artery roads and local roads, as shown in Fig. 6. However, there is an obvious difference in the vehicle emissions scenario between emissions on weekdays and weekends. For all road types, the temporal variations of vehicle emissions are much closer to the traffic flow, occurring separately at two emission peaks in the morning and afternoon. The daytime emissions account for approximately $70 \%$ of the daily total emissions because most private and business activities are conducted during the daytime.

\subsubsection{Spatial variation in emissions}

As a result of the vehicle emission inventory model, the spatial distribution of emissions has a strong correlation with the location of Beijing. Table 3 summarize the emission intensities in different areas of Beijing on weekdays and weekends. For both weekdays and weekends, vehicle emission intensities in the centre area of the city are higher than in the outside areas. The area between the second and third ring has 
$N$
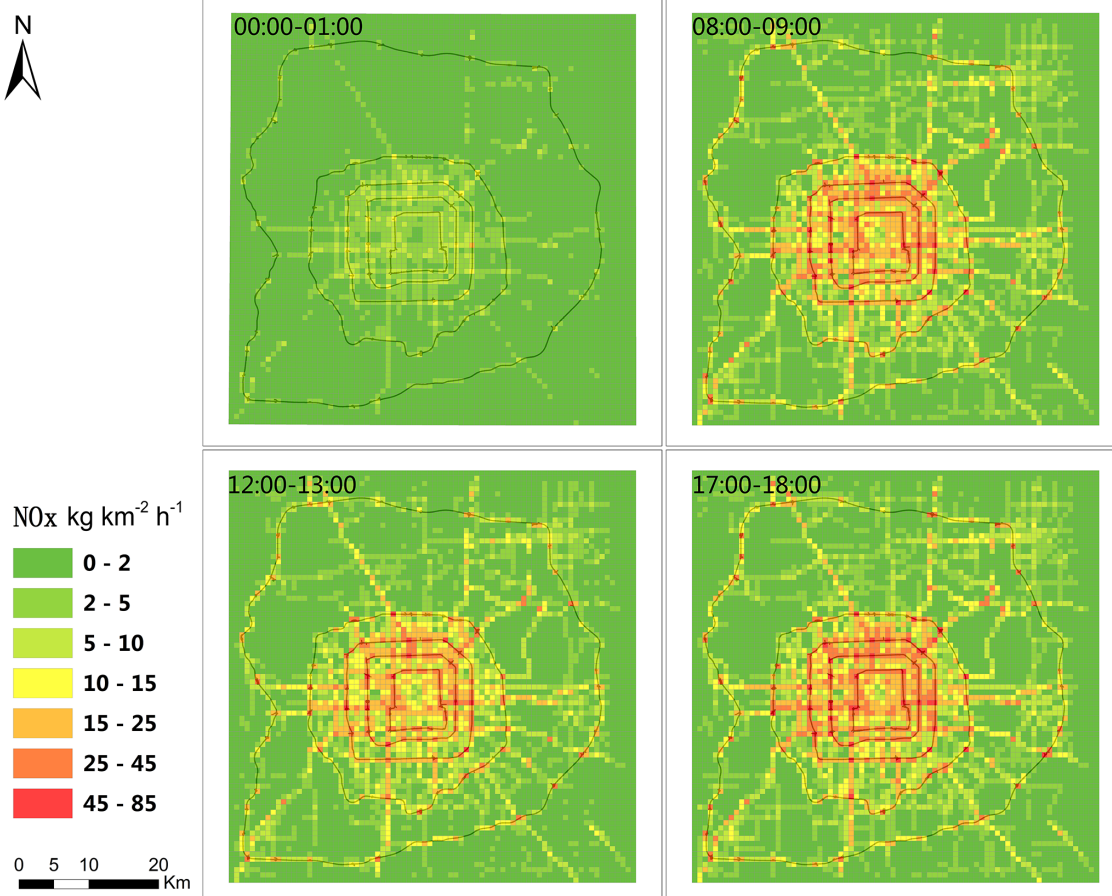

Figure 5. Grid-based vehicle emission inventory of $\mathrm{NO}_{x}$ in Beijing.

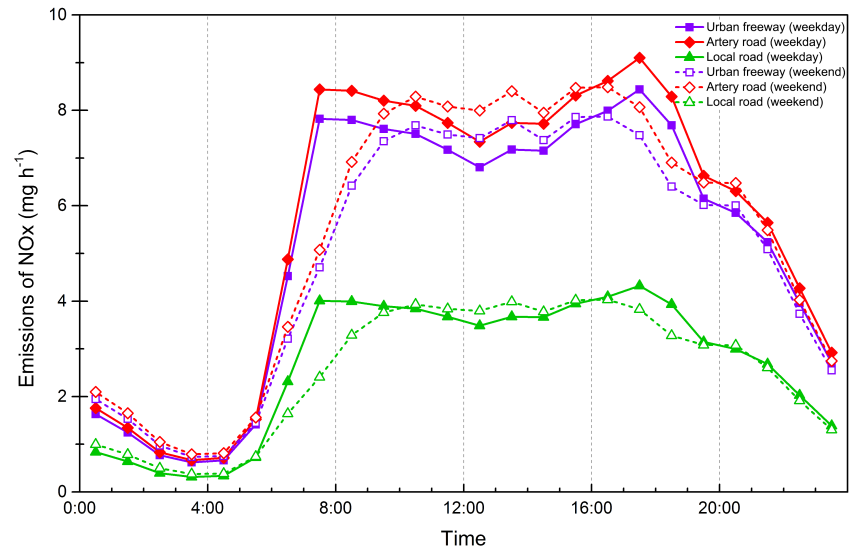

Figure 6. Hourly variation of vehicle emissions by road type on weekdays and weekends.

the strongest emission intensity because of its intensive road system and intense traffic activities (shown as higher volume and lower traffic speed). Although the urban centre (within the second ring) has the highest traffic density and the lowest traffic speed, the high density of freeways and artery roads in the area between the second and third ring causes the highest vehicle emission intensities, which is consistent with the forecast in 2004 that the emission intensities in the areas between the second and fourth rings could be as high as those in the urban centre, caused by rapid construction on the outside of the city centre (Huo et al., 2009).

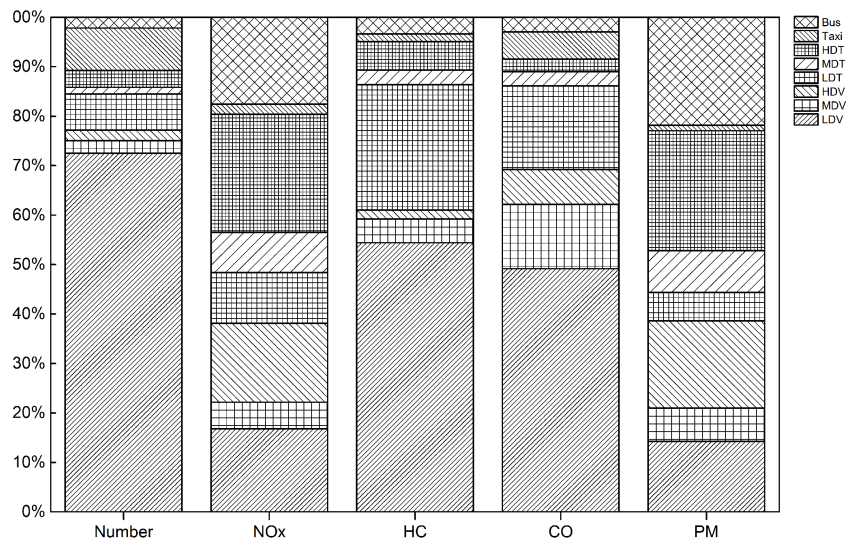

Figure 7. The vehicle emission contribution of different vehicle types.

\subsubsection{Contribution of vehicle classification}

Each on-road vehicle is used for the estimation of the bottomup vehicle emissions. The contribution of different vehicle types is shown in Fig. 7. Although the number of LDVs is highest, their $\mathrm{NO}_{x}$ and $\mathrm{PM}$ emission contributions are lower than those of HDTs and buses; their PM emissions are even lower than those of HDVs. The HC and CO emission contributions of LDVs and HDTs account for the largest proportion. As shown in Fig. 8, the vehicles with lower emission control levels have the higher emission contributions. 
Table 3. Daily vehicle emission intensities within different areas of Beijing (unit: $10^{4} \mathrm{Mg} \mathrm{km}^{-2}$ ).

\begin{tabular}{llrrrr}
\hline Date & Ring & $\mathrm{NO}_{x}$ & $\mathrm{CO}$ & $\mathrm{HC}$ & $\mathrm{PM}$ \\
\hline \multirow{2}{*}{ Weekdays } & Within the second ring & 0.377 & 1.520 & 0.076 & 0.015 \\
& Between the second and third ring & 0.411 & 1.656 & 0.083 & 0.016 \\
& Between the third and fourth ring & 0.366 & 1.477 & 0.074 & 0.014 \\
& Between the fourth and fifth ring & 0.201 & 0.810 & 0.041 & 0.008 \\
& Between the fifth and sixth ring & 0.058 & 0.234 & 0.012 & 0.002 \\
\hline \multirow{2}{*}{ Weekends } & Within the second ring & 0.368 & 1.483 & 0.074 & 0.014 \\
& Between the second and third ring & 0.389 & 1.567 & 0.078 & 0.015 \\
& Between the third and fourth ring & 0.347 & 1.398 & 0.070 & 0.013 \\
& Between the fourth and fifth ring & 0.186 & 0.749 & 0.037 & 0.007 \\
& Between the fifth and sixth ring & 0.057 & 0.230 & 0.012 & 0.002 \\
\hline
\end{tabular}

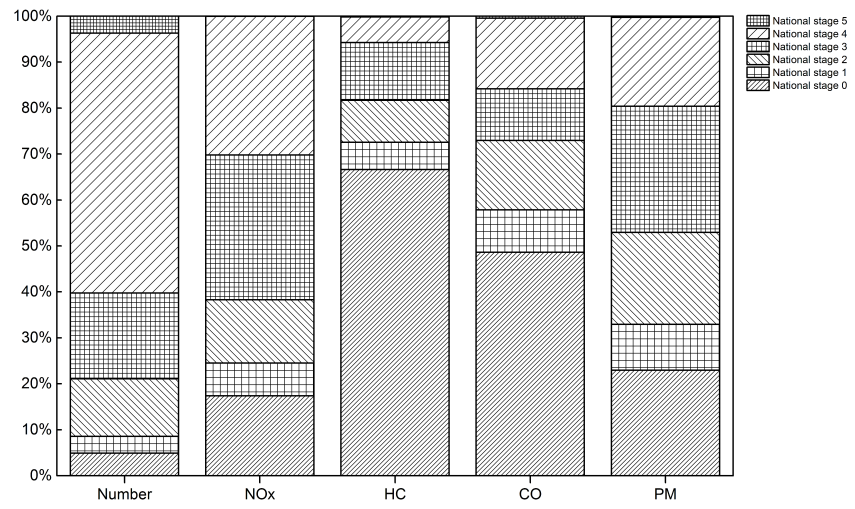

Figure 8. The vehicle emission contribution of different emission control level.

\subsubsection{Comparison between fuel consumption and fuel sales}

Based on the fuel consumption factors and vehicle activities, the fuel consumption of on-road vehicles was calculated by this model. The gasoline and diesel consumption was $429.63 \times 10^{4}$ and $141.02 \times 10^{4} \mathrm{Mg}$ respectively for the Beijing urban core area in 2013. According to the data from the petroleum sale company, the retail sales of gasoline and diesel fuel for the area in 2013 were $364 \times 10^{4}$ and $121 \times 10^{4} \mathrm{Mg}$ respectively. However, the consumption of gasoline and diesel was 18 and $16.5 \%$ higher than the sales of gasoline and diesel respectively because out-of-town vehicles driving into Beijing commonly refuelled outside the city.

In order to estimate the effects of out-of-town vehicles on fuel consumption calculation, the number of permits issued to out-of-town vehicles upon entering Beijing, collected from the Beijing Vehicle Emission Management Centre, was investigated along with their travel distance and time. The statistical results shows that there were 80 million out-of-town vehicles driving into Beijing, and each vehicle travelled 2 days in Beijing with a distance of $100 \mathrm{~km}$ per day. Accord- ing to the above statistics, the VKT of out-of-town vehicles accounts for $12.6 \%$ of the total VKT. When the fuel consumption of the out-of-town vehicles is added, the total fuel consumption values are closer to the fuel sale values.

\subsection{Comparison with other inventories}

Table 4 illustrates some uncertainties that exist in HTSVE after a comparison with the vehicle emission inventory known as the Chinese Unified Atmospheric Chemistry Environment (hereafter refer to VECU) developed by the China Meteorological Administration (He et al., 2016) and the inventory of the China Vehicle Emission Control Annual Report (Ministry of Environmental Protection of the People's Republic of China, 2013). By comparing vehicle emissions between HTSVE and VECU, it is clear that $\mathrm{NO}_{x}$ and $\mathrm{HC}$ vehicle emissions in HTSVE are higher than in VECU, and $\mathrm{CO}$ and PM vehicle emissions in HTSVE are slightly lower than in VECU, as shown in Table 4. The vehicle emissions of $\mathrm{NO}_{x}$ and PM in the China Vehicle Emission Control Annual Report are in an agreement with the emissions in HTSVE, whereas the emissions of $\mathrm{HC}$ and $\mathrm{CO}$ show significant differences. Moreover, the HC emissions in HTSVE are higher than the $\mathrm{HC}$ emissions in VECU, but lower than the HC emissions in the China Vehicle Emission Control Annual Report. The spatial distributions of vehicle emissions for the Beijing urban area in HTSVE and VECU are shown in Fig. 9. This figure shows that the high temporal-spatial resolution in HTSVE would be helpful to accurately produce a numerical simulation of the air quality of the city.

In conclusion, HTSVE established in this paper was similar to to VECU and inventory of China Vehicle Emission Control Annual Report on the order of magnitude. However, HTSVE was indirectly evaluated by the comparison of fuel consumption and fuel sale values. This showed that HTSVE could be closed with the actual emissions of on-road vehicles. Meanwhile, HTSVE had an advantage over VECU regarding air quality numerical simulation (He et al., 2016), 
Table 4. Annual vehicle emissions in different reports (unit: $10^{4} \mathrm{Mg} \mathrm{yr}^{-1}$ ).

\begin{tabular}{lrrrrr}
\hline Species & Region & $\mathrm{NO}_{x}$ & $\mathrm{HC}$ & $\mathrm{CO}$ & PM \\
\hline HTSVE & Beijing & 10.54 & 2.13 & 42.51 & 0.41 \\
VECU (He et al., 2016) & Beijing & 5.85 & 1.62 & 64.29 & 0.48 \\
China Vehicle Emission Control Annual Report (2013) & Beijing & 8.69 & 8.61 & 78.11 & 0.41 \\
\hline
\end{tabular}

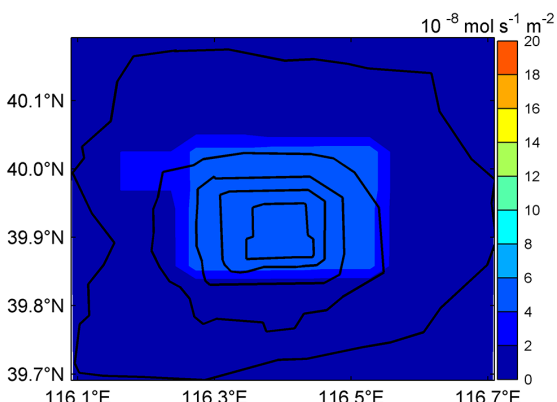

(a)

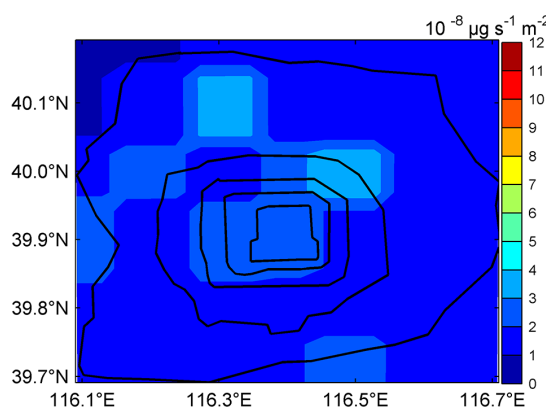

(c)

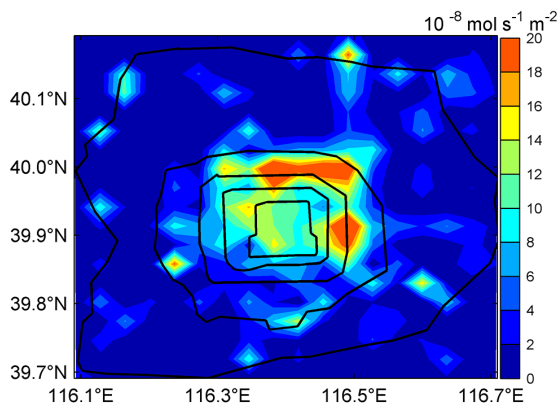

(b)

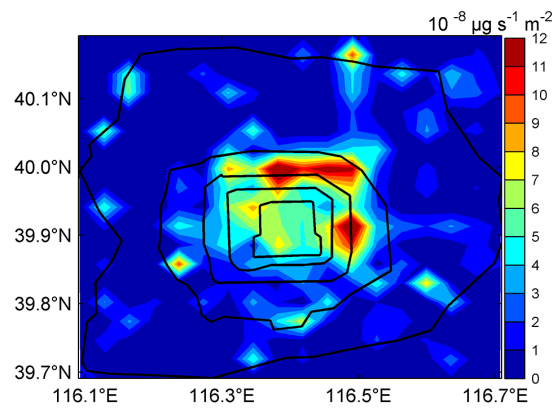

(d)

Figure 9. Spatial distributions of vehicle emissions in Beijing urban core area: (a) $\mathrm{NO}_{x}$ emissions in VECU, (b) $\mathrm{NO}_{x}$ emissions in $\mathrm{HTSVE}$ (c) PM emissions in VECU and (d) PM emissions in HTSVE.

which indicates that HTSVE can better depict vehicle emissions in temporal and spatial trends.

\section{Conclusions}

Both a bottom-up methodology using local emission factors and NRT traffic data are applied to estimate the emissions of on-road vehicles in the Beijing urban core area. The total vehicle emissions of $\mathrm{NO}_{x}, \mathrm{CO}, \mathrm{HC}$ and $\mathrm{PM}$ were $10.54 \times 10^{4}, 42.51 \times 10^{4}, 2.13 \times 10^{4}$ and $0.41 \times 10^{4} \mathrm{Mg}$ respectively for the Beijing urban area in 2013. In this paper, HTSVE shows high temporal-spatial resolution. The pollutant emissions from on-road vehicles show consistent temporal and spatial variation trends with the activity trends of people.

HTSVE established in this study can be extended in various ways. For example, it can be used to evaluate the impact of urban land plans on traffic emissions and the effect of traffic management measures on vehicle emissions reduction. Meanwhile, HTSVE can be transformed into an arbitrary scale grid according to the demands of the researcher. It can also be used as an accurate vehicle emission source inventory for air quality numerical simulation. In Part 2 of this project, the result shows that the accuracy of air quality simulation has been improved by using HTSVE.

Acknowledgements. This work was supported by the National Science and Technology Infrastructure Program (2014BAC16B03), China's National 973 Program (2011CB503801) and the National 863 Program (2012AA063303).

Edited by: X.-Y. Zhang

\section{References}

An, X., Zhu, T., Wang, Z., Li, C., and Wang, Y.: A modeling analysis of a heavy air pollution episode occurred in Beijing, At- 
mos. Chem. Phys., 7, 3103-3114, doi:10.5194/acp-7-3103-2007, 2007.

An, X. Q., Hong, Q., Li, N., and Zhai, S. X.: Assessment of human exposure level to $\mathrm{PM}_{10}$ in China, Atmos. Environ., 70, 376-386, doi:10.1016/j.atmosenv.2013.01.017, 2013.

Cai, H. and Xie, S.: Estimation of vehicular emission inventories in China from 1980 to 2005, Atmos. Environ., 41, 8963-8979, 10.1016/j.atmosenv.2007.08.019, 2007.

Chan, C. K. and Yao, X.: Air pollution in mega cities in China, Atmos. Environ., 42, 1-42, doi:10.1016/j.atmosenv.2007.09.003, 2008.

Cheng, S., Lang, J., Zhou, Y., Han, L., Wang, G., and Chen, D.: A new monitoring-simulation-source apportionment approach for investigating the vehicular emission contribution to the $\mathrm{PM}_{2.5}$ pollution in Beijing, China, Atmos. Environ., 79, 308-316, doi:10.1016/j.atmosenv.2013.06.043, 2013.

Cheng, S. Y., Chen, D. S., Li, J. B., Wang, H. Y., and Guo, X. R.: The assessment of emission-source contributions to air quality by using a coupled MM5-ARPS-CMAQ modeling system: A case study in the Beijing metropolitan region, China, Environ. Modell. Softw., 22, 1601-1616, doi:10.1016/j.envsoft.2006.11.003, 2007.

Fang, M., Chan, C. K., and Yao, X.: Managing air quality in a rapidly developing nation: China, Atmos. Environ., 43, 79-86, doi:10.1016/j.atmosenv.2008.09.064, 2009.

Fu, L. X., Hao, J. M., He, D. Q., He, K. B., and Li, P.: Assessment of vehicular pollution in China, J. Air. Waste. Manage., 51, 658668,2001

Guo, H., Zhang, Q., Shi, Y., and Wang, D.: On-road remote sensing measurements and fuel-based motor vehicle emission inventory in Hangzhou, China, Atmos. Environ., 41, 3095-3107, doi:10.1016/j.atmosenv.2006.11.045, 2007.

Hao, J. M., He, D. Q., Wu, Y., Fu, L., and He, K. B.: A study of the emission and concentration distribution of vehicular pollutants in the urban area of Beijing, Atmos. Environ., 34, 453-465, doi:10.1016/s1352-2310(99)00324-6, 2000.

He, J., Wu, L., Mao, H., Liu, H., Jing, B., Yu, Y., Ren, P., Feng, C., and Liu, X.: Development of a vehicle emission inventory with high temporal-spatial resolution based on NRT traffic data and its impact on air pollution in Beijing - Part 2: Impact of vehicle emission on urban air quality, Atmos. Chem. Phys., 16, 31713184, doi:10.5194/acp-16-3171-2016, 2016.

He, K. B., Huo, H., and Zhang, Q.: Urban air pollution in China: Current status, characteristics, and progress, Annu. Rev. Energ. Env., 27, 397-431, doi:10.1146/annurev.energy.27.122001.083421, 2002.

Heeb, N. V., Forss, A. M., Saxer, C. J., and Wilhelm, P.: Methane, benzene and alkyl benzene cold start emission data of gasoline-driven passenger cars representing the vehicle technology of the last two decades, Atmos. Environ., 37, 5185-5195, doi:10.1016/j.atmosenv.2003.04.001, 2003.

Hooper, E., Chapman, L., and Quinn, A.: The impact of precipitation on speed-flow relationships along a UK motorway corridor, Theor. Appl. Climatol., 117, 303-316, doi:10.1007/s00704-0130999-5, 2014.

Hu, J., Wu, Y., Wang, Z., Li, Z., Zhou, Y., Wang, H., Bao, X., and Hao, J.: Real-world fuel efficiency and exhaust emissions of light-duty diesel vehicles and their correlation with road conditions, J. Environ. Sci., 24, 865-874, doi:10.1016/s10010742(11)60878-4, 2012.

Huo, H., Zhang, Q., He, K. B., Wang, Q. D., Yao, Z. L., and Streets, D. G.: High-resolution vehicular emission inventory using a linkbased method: A case study of light-duty vehicles in Beijing, Environ. Sci. Technol., 43, 2394-2399, doi:10.1021/es802757a, 2009.

Karlsson, H. L.: Ammonia, nitrous oxide and hydrogen cyanide emissions from five passenger vehicles, Sci. Total Environ., 334, 125-132, doi:10.1016/j.scitotenv.2004.04.061, 2004.

Ministry of Environmental Protection of the People's Republic of China: China Vehicle Emission Control Annual Report, Ministry of Environmental Protection of the People's Republic of China, China, 6-9, 2013.

Naranjo, J. E., Jimenez, F., Serradilla, F. J., and Zato, J. G.: Floating car data augmentation based on infrastructure sensors and neural networks, IEEE T. Intell. Transp., 13, 107-114, doi:10.1109/TITS.2011.2180377, 2012.

Reynolds, A. W. and Broderick, B. M.: Development of an emissions inventory model for mobile sources, Transport. Res. D-Tr. E., 5, 77-101, doi:10.1016/S1361-9209(99)00025-5, 2000.

Song, Y., Xie, S., Zhang, Y., Zeng, L., Salmon, L. G., and Zheng, M.: Source apportionment of $\mathrm{PM}_{2.5}$ in Beijing using principal component analysis/absolute principal component scores and UNMIX, Sci. Total. Environ., 372, 278-286, doi:10.1016/j.scitotenv.2006.08.041, 2006.

Wang, H. K., Chen, C. H., Huang, C., and Fu, L. X.: Onroad vehicle emission inventory and its uncertainty analysis for Shanghai, China, Sci. Total Environ., 398, 60-67, doi:10.1016/j.scitotenv.2008.01.038, 2008.

Wang, H. Z., Ni, D. H., Chen, C. Y., and Li, J.: Stochastic modeling of the equilibrium speed-density relationship, J. Adv. Transport., 47, 126-150, doi:10.1002/atr.172, 2013.

Wang, T. and Xie, S.: Assessment of traffic-related air pollution in the urban streets before and during the 2008 Beijing Olympic Games traffic control period, Atmos. Environ., 43, 5682-5690, doi:10.1016/j.atmosenv.2009.07.034, 2009.

Wang, Z., Wu, Y., Zhou, Y., Li, Z., Wang, Y., Zhang, S., and Hao, J.: Real-world emissions of gasoline passenger cars in Macao and their correlation with driving conditions, Int. J. Environ. Sci. Te., 11, 1135-1146, doi:10.1007/s13762-013-0276-2, 2013.

Wu, Q. Z., Xu, W. S., Shi, A. J., Li, Y. T., Zhao, X. J., Wang, Z. F., Li, J. X., and Wang, L. N.: Air quality forecast of $\mathrm{PM}_{10}$ in Beijing with Community Multi-scale Air Quality Modeling (CMAQ) system: emission and improvement, Geosci. Model Dev., 7, 2243-2259, doi:10.5194/gmd-7-2243-2014, 2014.

Wu, Y., Zhang, S. J., Li, M. L., Ge, Y. S., Shu, J. W., Zhou, Y., Xu, Y. Y., Hu, J. N., Liu, H., Fu, L. X., He, K. B., and Hao, J. M.: The challenge to $\mathrm{NO}_{\mathrm{x}}$ emission control for heavy-duty diesel vehicles in China, Atmos. Chem. Phys., 12, 9365-9379, doi:10.5194/acp12-9365-2012, 2012.

Zhou, X., Tanvir, S., Lei, H., Taylor, J., Liu, B., Rouphail, N. M., and Christopher Frey, H.: Integrating a simplified emission estimation model and mesoscopic dynamic traffic simulator to efficiently evaluate emission impacts of traffic management strategies, Transport. Res., 37, 123-136, doi:10.1016/j.trd.2015.04.013, 2015. 